\title{
Adsorption Isotherms of Phenol Onto Adsorbents Derived from Egg Shell and Palm-Oil Shell
}

\author{
Rayandra Asyhar \\ Department of Chemistry Education, Faculty of Education, Jambi University, Mendalo Jambi 36136 \\ Diterima 27-01-2010 Disetujui 24-01-2011
}

\begin{abstract}
The adsorption isotherms of phenol from aqueous solution onto adsorbents obtained from egg shell (ESA) and palm shell (PSA) were investigated. The objectives of the investigation were to understand the effect of both adsorbents on solution $\mathrm{pH}$ and to study the adsorption equilibrium of phenol onto the adsorbents. The effect of adsorbent on $\mathrm{pH}$ of solution was studied by shaking the adsorbent of 0.1 to $1.5 \mathrm{~g}$ with $100 \mathrm{ml}$ of acidic aqueous solution for $30 \mathrm{~min}$ at room temperature. The adsorption experiments were performed by stirring appropriate amount of adsorbent with $100 \mathrm{ml}$ of $50 \mathrm{mg} / \mathrm{l}$ concentration of phenol at constant temperature and pressure. The Langmuir and Fraundlich adsorption models were applied to experimental data and the isotherm constants were calculated using linier regression analysis. The results showed that the adsorption capacity of the adsorbents increases with increasing of dosage and contact time. Also, $\mathrm{pH}$ of solution affected the adsorption isotherm of phenol, where maximum adsorption was observed at $\mathrm{pH}$ values lower than 9.
\end{abstract}

Keywords: adsorption, egg shell, equilibrium, palm-oil shell, phenol

\section{INTRODUCTION}

Phenol and phenolic derivatives were commonly encountered in aquatic environment (Gupta et al., 1998; Flock et al., 1999). Potential sources of phenolic compounds include the production and use of phenol and its products in industrial processes. Many industries such as petroleum industry, chemical, plastics, pharmaceutical, drugs, wood, pulp and paper, and phenolic resin industries released large quantities of wastewater containing varieous concentration of phenolics (Juang et al., 1998; Asyhar, 2002a). Because of their toxicity and carcinogenity, phenol and its derivatives are known as organic pollutants. Phenolic compounds are able to cause bad taste and odor, even at low concentration. According to Deanna and Shieh (1986), phenolic compounds are one of the 9 groups of harmful pollutants and therefore, they are included the main parameters and priorities of environmental water and wastewater quality.

Investigations of phenol and phenolic derivatives adsorption have been reported by previeous researchers. Juang et al., (1998), investigated adsorption isotherm of phenol on activated carbon fiber, whereas Asyhar (2002b), applied petroelum coke as

Telp: +6281367728985

Email: asyhar_r@hotmail.com raw material of activated carbon for the adsorption of phenol and 4-nitrophenol. This study was continued to investigate the equilibrium and adsorption model (Asyhar, 2002c). In the present paper it is reported an investigation of applying the adsorbents derived from chicken egg shells and palm shell towards phenol. The choice of egg shell is based on investigations reported by Van der Weijden and Comans (1997), and Wenming et al., (2001), that such material is mainly composed of calcium carbonate, i.e. calcite and calcareous soil, and they should be known as adsorbents. This asumption is supported by the report of Yeddou and Bensmaili (2007), that showed adsorption activity of egg shell towards metal iron. Moreover, palm-oil shell is already well known as a source of activated carbon. The techniques for the activated carbon production from this agricultural by-product were published by previeous researchers (Wan Nik et al., 2006). Activated carbon from palm-oil shell has also be reported by Vilisand et al., (1999).

\section{MATERIALS AND METHODS}

Egg shell preparation. Chicken egg shell samples obtained from Bakery Home Industries in Jambi City were washed with tap water and dried at 50 to 
$60^{\circ} \mathrm{C}$ for 2 hours in an oven. Then, egg shell membrans were separated and washed three times with distilled water. Afterwards, the sample was placed in an electric oven and dried for 2 to 3 hours at $70^{\circ} \mathrm{C}$. The dried egg shell adsorbent (ESA) was crushed and screened through a set of sieves of 50 mesh size to obtain the appropriate particles.

Production of adsorbent from palm shell. The raw material of palm shell taken from PTP. Nusantara VI Mill Sungai Bahar Kabupaten Batanghari Jambi. The material was washed with water and dried in an oven. After drying, the shell was soaked with $10 \%$ acid solution and immersed in this solution for 24 hours to loose the fibre and traces. The wastes floated at the surface of solution were then separated by applying distilled water. According to Wan Nik et al., (2006), this treatment is important part to make sure the adsorbents that would be produced are of good quality. The shell materials were taken the weight $20.0 \mathrm{~g}$, then sunk with $100 \mathrm{ml}$ of freshly prepared solution of $30 \% \mathrm{H}_{3} \mathrm{PO}_{4}$. The mixture was carbonized at $600^{\circ} \mathrm{C}$ for 2 hours in a stainless tube of $20 \mathrm{~cm}$ inside diameter and $50 \mathrm{~cm}$ length as designed by Vitidsant et al., (1999). The activated carbon products were washed several times with water to obtain neutral $\mathrm{pH}$ followed by dried in an oven at $105^{\circ} \mathrm{C}$ for 2 hours. The palm shell adsorbent (PSA) was then crushed and shieved to obtain particles of 50 mesh.

Effect of adsorbent on $\mathrm{pH}$ of solution. The effect of adsorbent material on $\mathrm{pH}$ of solution was studied by shaking the adsorbent with dosages varied of 0.1 to $1.5 \mathrm{~g}$ with $100 \mathrm{ml}$ of acidic aqueous solution $(\mathrm{pH}=3.2)$ for $30 \mathrm{~min}$ at room temperature $\left( \pm 30^{\circ} \mathrm{C}\right)$. The solid materials were filtered out from solution through a filter paper before measuring their $\mathrm{pHs}$ with a digital $\mathrm{pH}$ meter.

Isotherm adsorption experiments. The reaction vessels used in all experiments were $100 \mathrm{ml}$ Erlenmeyer flasks with glass stoppers. Each glass was prewashed with $10 \% \mathrm{HNO}_{3}$ solution, rinsed with demineralized water, and air-dried at $110^{\circ} \mathrm{C}$ for 2 hours prior to usage. A magnetic stirrer was used to mix the solution, and a glass beaker was, as a conventional thermostat, used to maintain a constant temperature. The experiments were undertaken in a little dark by means of covering the outside of the beakers with aluminum foil. The beakers were maintained at $\pm 1^{\circ} \mathrm{C}$ to the desired temperatures and a normal pressure (1 atm).
Experiments were performed by adding $100 \mathrm{ml}$ of phenol solution with a $50 \mathrm{mg} / \mathrm{l}$ concentration to 0.1 to $2.0 \mathrm{~g}$ of adsorbent. Into the solution, 20 drops of buffer were needed to adjust the $\mathrm{pH}$ to 2 to 12 prepared according to procedure described in Asyhar (2002a). The flasks were then put in a thermostat at constant-temperature of $30^{\circ} \mathrm{C}$ and stirred continuously with a speed of 300 rpm for a period of time 0 to $180 \mathrm{~min}$. After equilibration, the supernatant liquid was filtered through blue ribbon filter paper with a $125 \mathrm{~mm}$ (S \& S) prior to analysis, in order to minimize interference of the adsorbent fines with the analysis. The concentrations of phenol in the residual solutions were determined using UV-visible spectrophotometry at $270 \mathrm{~nm}$ wavelength. The removal efficiency of phenol solution was calculated from:

$\%$ Removal $=C_{\mathrm{i}}-C_{\mathrm{f}} \times 100 / C_{\mathrm{i}}$

The adsorption capacity of adsorbent is the concentration of phenol on the adsorbent and calculated based on the balance principle

$q=V\left(C_{i}-C_{f}\right) / m$

where $q$ represents the amount of phenol uptake per unit mass of adsorbent $(\mathrm{mg} / \mathrm{g}), V$ is the volume of the solution (I), $m$ is the dry mass of the adsorbent $(\mathrm{g})$, $C_{i}$ and $C_{f}$ - initial and final concentrations $(\mathrm{mg} / \mathrm{l})$, respectively.

\section{RESULTS AND DISCUSSIONS \\ Effect of sorbents towards pH of solution.}

Figure 1 shows that adsorbent obtained from egg shell significantly affects $\mathrm{pH}$ of solution. It can be seen that the $\mathrm{pH}$ increase with increasing of egg shell dosages. A maximum increase of $\mathrm{pH}$ was almost achieved by adding $0.5 \mathrm{~g}$ of egg shell to $100 \mathrm{ml}$ of test solution, indicating the optimum dosage of the egg shell. The capability of egg shell in increasing $\mathrm{pH}$ may be explained from the chemical composition of egg shell mainly containing basic components, i.e. calcite and calcareous materials (Yeddou \& Bensmaili, 2007).

Different from egg shell, activated carbon from palm shell does not affect $\mathrm{pH}$ of solution. This can be seen from Figure 1 that there is no significant difference in hight of $\mathrm{pHs}$ graphs before and after agitating process, indicating that there is no influenced of adsorbents from palm shell towards $\mathrm{pH}$ of solution. 
Effect of contact time. The adsorption experiments were carried out to determine the contact time required to attain equilibrium condition. $0.5 \mathrm{~g}$ of adsorbent was stirred with $100 \mathrm{ml}$ of test solution having a concentration of $50 \mathrm{mg} / \mathrm{l}$ at a constant temperature $\left(30^{\circ} \mathrm{C}\right)$ and adjusted $\mathrm{pH}$ of 6.0 for a time period of 0 to $180 \mathrm{~min}$. The quantity of the adsorbed phenol from solution was plotted as a function of time. The adsorption of both adsorbents to phenol shows generally the similar trend where the adsorption process is a function of contact time as depicted in Figure 2.

The amounts of phenol adsorbed by adsorbents were progressively increased as the contact time increased, and then gradually attained equilibrium in $30 \mathrm{~min}$ for the adsorbents both derived from egg shell (ESA) and palm shell (PSA). Within the first $15 \mathrm{~min}$, the adsorption by PSA occurred rapidly, where more than $50 \%$ of phenol concentrations were reduced within this period of time. No significant change in percent uptakes of adsorbate was observed after $60 \mathrm{~min}$. The equilibrium of the adsorption was almost completely reached after $90 \mathrm{~min}$. A similar trend of adsorption is

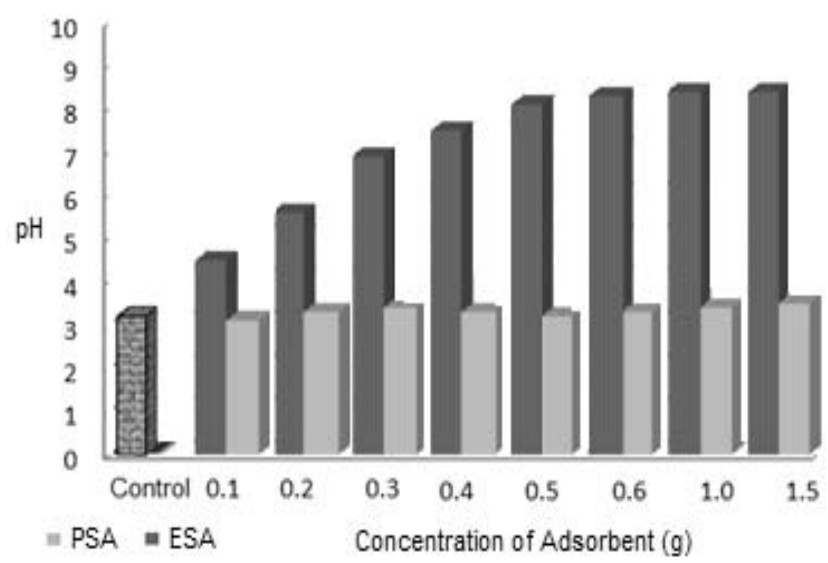

Figure 1. Effect of adsorbents towards $\mathrm{pH}$ of aqueous solution

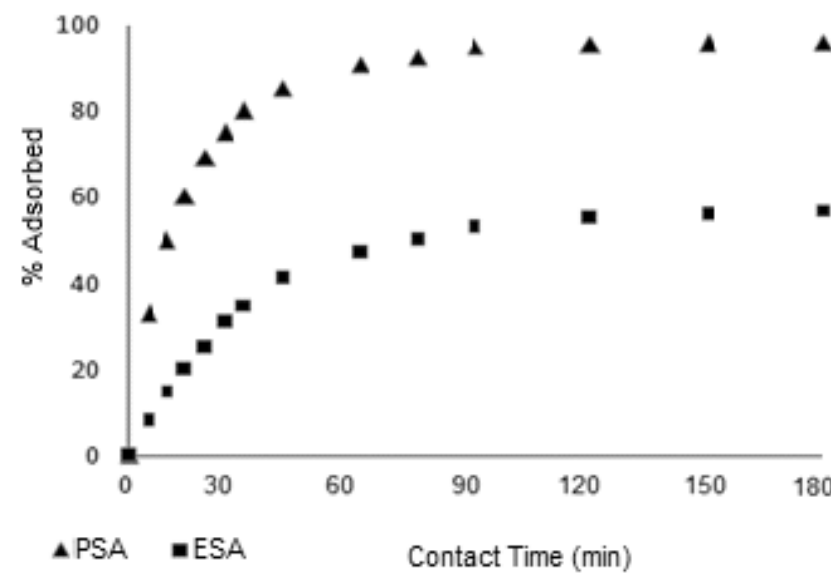

Figure 2. Adsorption of phenol onto ESA and PSA as a function of time shown by adsorbent from egg shell (ESA) but in a lower capacity and slower rate. The relatively small amount of phenol removed from its solution by ESA attributes to lack of their interaction compared to PSA. In order to ensure the completion of the adsorption process of phenol, further experiments for the evaluation purposes should be done by stirring each reaction mixture for up to $180 \mathrm{~min}$, even though an adsorption period of $90 \mathrm{~min}$ is sufficient to reach equilibrium.

Effect of adsorbent dosages. Figure 3 shows the reduction of phenol by variation of amounts of the sorbents. As the amount of adsorbents used increased, the removal of the phenol also increased. The increase in the removal of phenol by PSA was much greater than that by ESA. It was observed that almost completely phenol was adsorbed from solution by applying $0.5 \mathrm{~g}$ of adsorbent from PSA. As for ESA, it was observed that a maximum amount of phenol reduced from solution by $1 \mathrm{~g}$ of adsorbent was only $51.0 \mathrm{mg}$. The higher adsorption capability of the adsorbent from PSA is presumed as a result of similar physical properties where both phenol and activated carbon are known as neutral matters. ESA, as a carbonate-rich material, has a polar side in it molecules, and its polarity is higher than PSA, so that the interaction between ESA and the neutral phenol molecules is weaker. That means that the phenol molecules solution weak.

Effect of $\mathrm{pH}$ to adsorption capacity. The effect of $\mathrm{pH}$ to the adsorption capacity of both adsorbents towards phenol was investigated. Both adsorbents strongly adsorbed both at $\mathrm{pH}$ values lower than 9 . The horizontal plateaus in Figure 4 between $\mathrm{pH}$ values 2 and 10 indicate that no significant influence of hydronium ions $(\mathrm{pH})$ within these $\mathrm{pH}$ ranges.

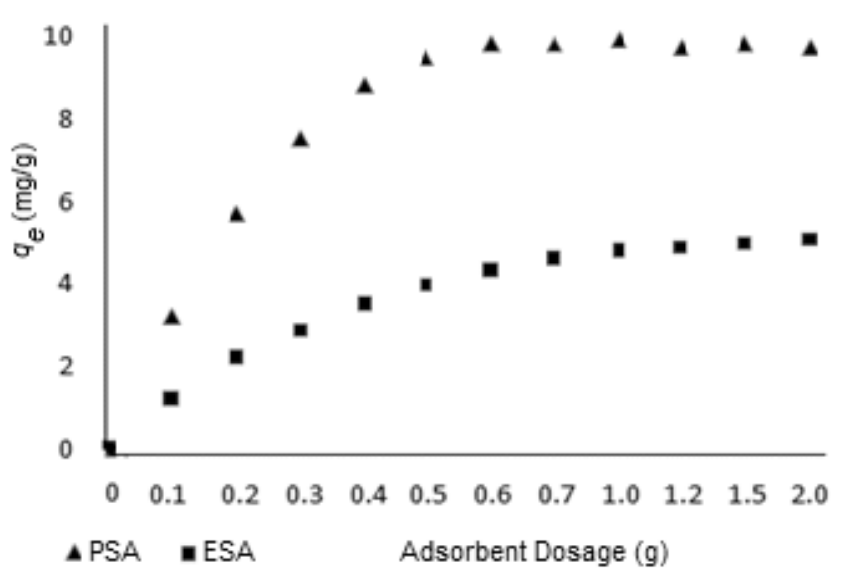

Figure 3. Effect of adsorbent dosage to phenol adsorption (Cond.: $T=30^{\circ} \mathrm{C}, C=50 \mathrm{mg} / \mathrm{l}, V=100 \mathrm{ml}, t=90 \mathrm{~min}$ ) 
A rapid decrease in the removal amounts occurs at $\mathrm{pH}$ values greater than 10 . It is observed that the removal rate of phenol adsorbed by adsorbents decreases with the rise of $\mathrm{pH}$. The decreases in adsorption can be explained on the basis of dissociation of phenol in aqueous solution as anionic phenolates which did not adsorb well on the hydrophobic surface of activated adsorbents. At a higher $\mathrm{pH}$, phenol dissociates into phenolate ion and hydronium ion which is more soluble in aqueous solution. The dissociated phenols should be less adsorbed because of the stronger adsorbate-solvent bond affects the affinity for the adsorbate.

From the data of the $\mathrm{pH}$ dependence of the adsorption it can be concluded that the optimum condition of phenol removal from an aqueous solution can be undertaken at pHs below 9. This may be explained by using dissociation factor of phenol.

Adsorption isotherm model. The modelling of adsorption equilibrium has been achieved by applying both the Langmuir and Freundlich isotherms represented mathematically by equations (3) and (4), respectively:

$C_{\mathrm{e}} / q_{\mathrm{e}}=1 / Q^{\circ} b_{\mathrm{L}}+C_{\mathrm{e}} / Q^{\circ}$

$\ln q_{\mathrm{e}}=\ln K_{\mathrm{F}}+1 / n \ln C_{\mathrm{e}}$

The Langmuir constants, $b$ and $Q^{\circ}$, were obtained from the slope and the intercept of a plot of $C / q$ against $C$, and the Freundlich parameter values were obtained from a linear graph of $\ln q_{\mathrm{e}}$ against $\ln C$, i.e., $n$ from the slope and $K_{F}$ from the intercept. The Langmuir and Frendlich isotherm parameters for the adsorption of phenol onto adsorbents from egg shell and palm shell are summarized in Table 1. The linearized plots obtained

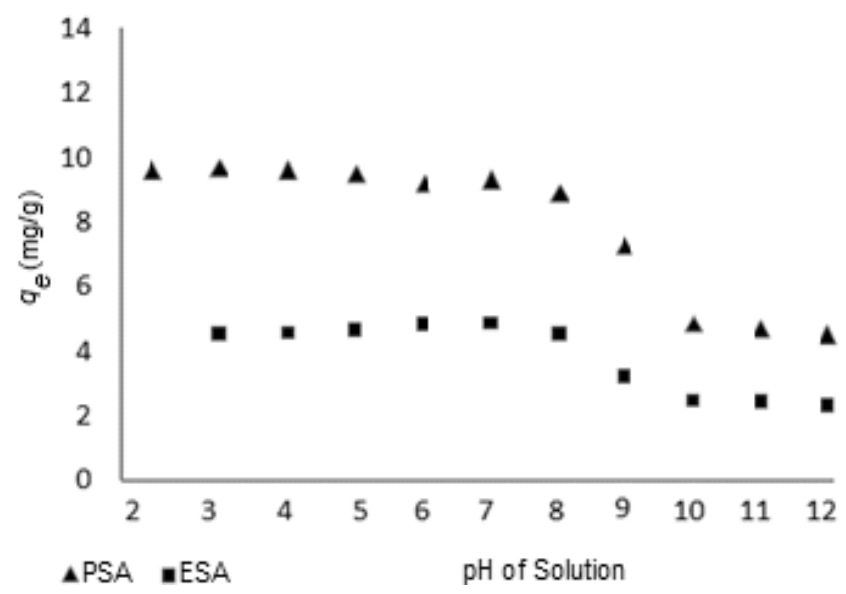

Figure 4. Effect of $\mathrm{pH}$ on adsorption phenol (Cond: $T=30^{\circ} \mathrm{C}$, $\left.C_{\text {soln. }}=50 \mathrm{mg} / \mathrm{l}, V=100 \mathrm{ml}, W_{\text {sorbent }}: 0.5 \mathrm{~g}\right)$ for the adsorption of phenol onto adsorbents derived from egg shell and palm shell were indicated by the linearities, $R^{2}$, in Table 1, comfirming the validity of the Langmuir model for the adsorption. These isotherm analysis data show that the adsorptive behavior of phenol onto sorbents from egg shell and palm shell agreed with Langmuir rather than with the Freundlich isotherm, indicating that the adsorption was achieved with the formation of a monolayer.

It can be concluded that the adsorption capacity of adsorbent derived from egg shell towards phenol is very small compared to those of palm-oil shell, indicating that the egg shell sorbent is not effective for the removal of phenol.

\section{CONCLUSIONS}

The investigations of isotherm adsorption of phenol onto adsorbents derived from egg shell (ESA) and palm shell (PSA) were performed. The experimental results indicated that several factors such as contact time, $\mathrm{pH}$ of solution and adsorbent dosage affect the adsorption process. Adsorbents from egg shell increase $\mathrm{pH}$ of solution, whereas adsorbents obtained from palm-oil shell did not significantly affect $\mathrm{pH}$. The maximum adsorptions of phenol were obserbed at pHs below 9 . The linearized plots obtained for the adsorption of phenol onto ESA and EPA were indicated by the linearities, $R^{2}$, comfirming the validity of the Langmuir model for the adsorption. The isotherm analysis results show that the adsorptive behavior of phenol onto adsorbents from egg shell and palm shell agreed with Langmuir rather than with the Freundlich isotherm.

\section{ACKNOWLEDGEMENTS}

The author greatly acknowledge sincerely the Directorate General of Higher Education (DIKTI) for the financial support of this studies through funding Penelitian Hibah Bersaing with contract no. 46/H21.3.1/ 2.4/2009.

\section{REFERENCES}

Asyhar, R. 2002a, Activation of Petroleum Coke and Its Application for the Removal of Phenols and Dyes from Waste Water, $S$ 3 Dissertation, Tecnical University Braunschweig, Germany.

Asyhar, R. 2002b, Preparation of Active Adsorbent from Petroleum Coke and Its Application for Phenol and 4-Nitrophenol Reduction from Aqueuos Solution, Fresenius Environ. Bull. 3(1): 149-155.

Asyhar, R. 2002c, Equlibrium Studies of Activated Petroleum Coke Towards Phenol and 4-Nitrophenol, Fresenius Environ. Bull. 6(1): 272-279. 
Deanna \& Shieh. (1986), Biological fate of organic priority pollutants in the aquatic environment, Wat. Res., 20(9): 10771090.

Flock, C., Bassi, A. \& Gijzen, M. (1999), Removal of aqueous phenol and 2-chlorophenol with purified soybean peroxidase and raw soybean hulls, J. Chem. Technol. Biotechnol. 74: 303-309.

Gupta, V. K., Sharma, S., Yadav, I. S. \& Mohan, D. (1998), Utilization of bagasse fly ash generated in the sugar industry for the removal and recovery of phenol and p-nitrophenol from wastewater, J. Chem. Technol. Biotechnol. 71: 180186.

Juang, R-S, Wu, F. C. \& Tseng, R. L. (1998), Adsorption Isotherms of Phenolic Compounds from Aqueous Solutions onto Activated Carbon Fibers, J. Chem. Eng. Data, 41: 487492.

Van der Weijden, R. D. \& Comans, R. N. J. (1997), Sorption and Sorption Reversibility of Cadmium on Calcite in the Presence of Phosphates and Sulfates, Mar. Chem, 57(1/2): 119-132.
Vilidsand, T., Surafaltanasakul, T. \& Domrongklerd, S. (1999), Production of Activated Carbon from Palm-Oil Shell by Pyrolysis and Steam Activation in a Fixed Bed Reactor, Science Asia, 25: 211-222.

Wan Nik, W. H., Rahman, M. M., Yusuf, A. M., Ani, F. N. \& Adnan Che, C. M. (2006), Production of Activated Carbon from Palm Oil Shell Waste and Its Adsorption Characteristics, Proceedings of the $1^{\text {th }}$ International Conference on Natural Resources Engineering and Technology, 24-25th July 2006, Malaysia, 546-564.

Wenming, D. Zhijun, G., Jinzhou, D., Liying, Z. \& Zuji, T. (2001), Sorption Characteristics of Zinc (II) by Calcareous Soil-Radiotracer Study, Appl. Radiat. Isotopes, 54(3): 371375.

Yeddou, N. \& Bensmaili, A. (2007), Equlibrium and Kinetic Modelling of Iron Adsorption by Egg shells in a Batch System: Effect of Temperature, Desalination, 206: 127-134. 